\title{
La isla-mujer. Lo femenino como liberación en El beso de la mujer araña de M anuel Puig
}

\author{
The island-woman. Female as release in El beso dela mujer \\ araña by M anuel Puig
}

HERNANDO Escobar Vera

Instituto Caro y Cuervo, Colombia

nandoev@yahoo.es

\section{RESUMEN}

A través de El beso de la mujer araña se propone un estado de cosas caracterizado por las relaciones de dominación de unos sobre otros, estado que no se supera solamente a través dela revolución política, en el sentido restringido de lo político, sino que debe involucrar la liberación delos cuerpos através dela revolución sexual. M olina, una mujer atrapada en el cuerpo de un hombre y en las representaciones que la sociedad hace sobre ese cuerpo, y Valentín, un preso político, resguardados por la isla-mujer, transitan hacia la posibilidad de una realización, aprendizaje o devenir: M olina hacia un devenir mujer; Val entín, hacia un devenir persona, es decir, devenir polimorfo sexual. El beso es símbolo de la comunión entre los personajes y del encuentro de las revoluciones política y sexual. Pero en la obra no hay espacio para la utopía política: el sistema sigue controlando los cuerpos, fuera de la isla-mujer reinan la muerte y la tortura, un mundo que sigue esperando la revolución; en cambio, las sexualidades sí han sido liberadas y satisfechas.

Palabras claves: N ovela, M anuel Puig, homosexualidad, transgenerismo, revolución sexual, simbología femenina, crítica de la estructura patriarcal.

\section{ABST RACT}

Through El beso dela mujer araña it proposesa statusquo characterized by therelationships of domination of some over others, status that is not exceeded only through the political revolution, but must involvetherelease of the bodiesthrough the sexual revolution. M olina, a woman trapped in a man's body and in the representations that society makes on that body, and Valentín, a political prisoner, shielded by island-woman, aremoving toward the possibility of realization, learning or becoming: M olina toward a becoming into a woman; Valentín, toward a becoming into person, into sexual polymorphous. El beso is a symbol 
of communion between both characters and the gathering of political and sexual revolutions. But in the book there is no room for political utopia: the system still controls the bodies, outside the island-woman reign death and torture, a world that is still waiting for the revolution; instead, sexualities have been released and satisfied.

Keywords: N ovel, M anuel Puig, homosexuality, transgenerism, sexual revolution, female symbolism, criticism of the patriarchal structure.

Recibido: 10-12-2007. Aceptado: 25-03-2008.

$\mathrm{N}$ o, yo no mearrepiento denada. Cada vez meconvenzo más de que el sexo es la inocencia misma. (Valentín, El beso': 224)

ACQ UES M ercanton dice del soliloquio final de M olly Bloom, en el U lises de Joyce, que su "ritmo se une al movimiento de la tierra, se funde en el ritmo mismo del universo sensible", y más adelante pone a la mujer, la naturaleza y la tierra en un mismo plano, como sinónimos. M ercanton está acudiendo al mito, al origen de los símbolos, para buscar allí la tierra pasiva que se hace vida cuando la energía masculina la abre, la penetra y la fecunda; pero desnuda el símbolo de este sentido falogocéntrico y lo devuelve a su posibilidad de significar fuerza, expresada en ritmo y movimiento. En la relación que propone, entre la tierra y el hombre (lo femenino y lo masculino), no opone una fuerza (actividad) y una ausencia de fuerza (pasividad) sino que presenta dos fuerzas que pueden aceptarse o rechazarse. Anota:

Según una palabra del mismo Joyce, esta última imagen es para el hombre, Leopoldo Bloom (...) su pasaporte a la eternidad. Y la mujer, la natural eza, la tierra, se acuerda que el hombre la ha seducido, y es a él, como a toda la vida, a quien ella le dice sí (2).

Pero cuando la tierra (lo femenino) aparece en la forma de isla, resguardada de los hombres por las marejadas, simboliza la otredad, otro mundo donde es posible una vida mejor, otro mundo libre de los daños de la tierra continental. Este es el sentido dela isla-mujer en El beso dela mujer araña. Un mundo donde la felicidad sea posible es, en este caso, un mundo femenino liberado de la dominación masculina², libre del mito fundacional del falogocentrismo, resguar1976).

${ }^{1}$ Puig M anuel. 2002. El beso de la mujer araña. Barcelona: Seix Barral (primera edición de

${ }^{2}$ El narrador de El beso trae en n.a.p. este texto: "En Tres ensayos sobre la teoría de la sexualidad, Freud señala que la represión, en términos generales, proviene de la imposición de dominación de un individuo sobre otros, siendo ese primer individuo no otro que el padre. A partir detal domina- 
dado del continente (tierra dominada) por el mar: feminidad indómita, misterio para el hombre. Sin embargo, lo particular de la isla-mujer de El beso es que los mares que la resguardan son imaginarios, la historia transcurre en una celda, rodeada, a pesar de tales mares, por las inminentes y fácticas estructuras del poder patriarcal y heterosexista.

Juntos en la isla-celda se encuentran un "revolucionario" sexual (alguien a quien por la expresión anatómica de su cuerpo se le ha asignado la categoría de hombre, pero que se identifica como mujer), preso por corrupción de menores, cuya trasgresión del paradigma sexual es inconsciente, de hecho no tiene ningún tipo de conciencia política activista ni aspira a ninguna revolución, y un preso político, revolucionario de izquierda, quien conocerá, a través de su compañero de celda, los límites de una revolución inscrita en la misma lógica patriarcal de los reaccionarios que pretende combatir. Ambas son revoluciones incompletas y, por tanto, fallidas. Pero, resguardados por la isla-mujer, ambos personajes transitan hacia la posibilidad de una realización, aprendizaje o devenir: M olina hacia un devenir mujer; Valentín, un paso adelante de los géneros estereotípicos en los que M olina cifra su realización, hacia un devenir persona, es decir, devenir polimorfo sexual. Este devenir (real ización o aprendizaje), aunque no completal las nociones propuestas por el narrador de revolución sexual ni las del personaje, Valentín, de revolución social, sí implica un crecimiento delos personajes hacia formas más libres de ser.

D e esta manera queda planteado, mediante formas al egóricas y explícitas 3 , quela revolución sexual hace parteindispensable deuna revolución social ${ }^{4}$. Esta idea ya ha sido propuesta literariamente en el contexto latinoamericano por Cortázar en El libro de M anuel (1973), pero en El beso se postula que la liberación frente al paradigma heterosexista es fundamental para las dos liberaciones que son una. La obra denuncia la dominación patriarcal-heterosexista que controla los cuerpos en el terreno de lo público (masculino) mediante el aparato

ción, se establece la forma patriarcal de la sociedad, basada en la inferioridad de la mujer y en la fuerte represión de la sexualidad (...) Otto Rank considera el desarrollo que va de la dominación paterna hasta llegar a un poderoso sistema estatal administrado por el hombre, como una prolongación de dicha represión primera, cuyo propósito es la cada vez mayor exclusión de la mujer" (154).

${ }^{3}$ El proceso narrativo dominante es el montaje de voces y relatos. Los relatos metadiegéticos amplían el significado del acontecimiento diegético y las notas al pie enfatizan el sentido axiológico de manera explícita.

${ }^{4}$ Incluso, D above (1994) afirma que "El beso no variaría las presuposiciones de la novela ideológica tradicional, sino que ponien do en juego procedimientos aventurados y novedosos afinaría sus posibilidades" (13). Por su parte, M uñoz (1987) atribuye parte importante del valor literario de la obra de Puig a "la denuncia y apertura que sus textos hacen en la región de la (voz) sexual. D enuncia de las relaciones de poder dentro de las cuales se define la sexualidad en 0 ccidente y apertura hacia una nueva manera de entender y definir estas relaciones" (33). 
político coercitivo, y la dominación moral-sexual, que controla el cuerpo y la conciencia de él en el terreno de lo íntimo (femenino), a través de las normas de hecho escritas en la cultura y en las representaciones mentales de las personas. Los cuerpos en su dimensión pública, sujetos por las estructuras políticas, no son liberados (M olina muere, Valentín es torturado), pero las conciencias y los cuerpos en su dimensión sexual, sí: M olina es amado como una mujer, Val entín lleva su conciencia sexual (también conciencia política) al nivel de la práctica sexual.

La celda-isla es la concreción de la paradoja "cuerpo dominado-conciencia liberada". La celda es símbolo del poder opresor sobre los cuerpos en su dimensión pública (masculina), de vigilar y castigar, del control político de los discursos. Su sentido trasciende el solo espacio físico de la cárcel, se prolonga a través de la vigilancia ejercida sobre M olina por la institucionalidad (derecha) y a través de la "misión" que se le ha asignado (por la izquierda revolucionaria). La tensión entre opuestos irreconciliables se mantiene. Estos son las Flores negras que impiden la felicidad de la pareja cuyos sentimientos son libres, pero cuyos cuerpos pueden ser arrebatados por la fuerza de la institucionalidad (masculina). El orden del mundo-continenteno se puedealterar en el curso de la novela. En cambio, la isla es el espacio íntimo donde la utopía es posible. Allí obra la transformación. Fuera de allí están la muerte, la tortura y la sociedad alienada y sin equidad.

El punto de vista que prima en el discurso, en la medida en que tranforma a otro personaje, es el de M olina; el sujeto del aprendizaje, a través de ese discurso, es Valentín y, por medio de Valentín, el lector. Al respecto, M uñoz (1987) anota que "es importante que sea Valentín el portavoz de esta utopía, pues con él la novela subvierte el discurso patriarcal judeocristiano y las categorías de lo verosímil en la creación de un personaje, dándole al "macho revolucionario" una toma de conciencia que termina siendo una toma de la homosexual idad" (74).

Sin embargo, no es específicamentea favor dela homosexualidad la toma de conciencia deValentín, sino del polimorfismo sexual, la sexualidad liberada por la que abogan los teóricos citados por el narrador en notas al pie de página. Y la sexualidad liberada es lo femenino ${ }^{5}$ liberado, lo cual incluye la liberación de los hombres de la estructura patriarcal. El narrador lo expone a través de palabras de Roszak: "la mujer más necesitada, y desesperadamente, de liberación, es la 'mujer' que cada hombre lleva encerrada en los calabozos de su propia psiquis" (n.p.p.: 200).

M ostraré, entonces, el tránsito liberador de cada personaje hacia lo femeni-

${ }^{5} \mathrm{M}$ anrique (2000) afirma que Puig "entrevista tras entrevista, decía que el principio masculino era el responsable de la guerra y la destrucción" (88). 
no, el cual se hace posible en esa isla-cárcel que al final de la novela es percibida por el sobreviviente como lo que siempre fue: una isla-mujer. Como brújula de ese tránsito, ofrezco un esquema que sintetiza los campos semánticos del ideologema masculino-femenino, central de la novela:

$\begin{array}{ll}\text { Masculino } & \text { Femenino } \\ \text { Valentín } & \text { M olina } \\ \text { Celda } & \text { Isla } \\ \text { Racionalismo } \text { (libros }^{6} \text { ) } & \text { Imaginación (historias) } \\ \text { Divino } & \text { H umano } \\ \text { (heroísmo que niega la humanidad) } & \text { (humanidad liberada del deber-ser heroico) } \\ \text { Hombre } & \text { Animal } \\ \text { (en tanto civilizado-controlado) } & \text { (humanidad liberada del deber-ser civilizado) } \\ \text { Día } & \text { N oche } \\ \text { Público } & \text { Intimo } \\ \text { Dominación (sobre el cuerpo) } & \text { Liberación (de la conciencia del cuerpo) } \\ \text { Racionalidad } & \text { Corporalidad }\end{array}$

\section{HOM OSEXUALID AD Y FEMINID AD}

Es difícil prever las reacciones de Molina, un amoral en fin de cuentas (Director, El beso: 250)

Si el discurso de liberación que se propone en El beso no es sobre la homosexualidad sino sobre la feminidad, ipor qué ha sido elegido como motor del aprendizaje un hombre homosexual y no una mujer? $\mathrm{H}$ ay tres razones: 1 . denunciar la opresión sobre lo femenino a través de un tipo femenino estereotípico, 2. contrastar una masculinidad homosexual (hiperfemenina ${ }^{7}$ ) con una masculini-

${ }^{6}$ D above (1994) afirma que, en El beso, "las historias son una huida, los libros un modo superlativo de estar en la realidad" (17).

${ }^{7}$ Respecto a la relación homosexualidad-feminidad, Guasch (1995) explica la consolidación de la identidad homosexual a través de dos periodos, el pre-gay y el gay. Dice que entre "los rasgos fundamentales que caracterizan el periodo pregay en España" está "la construcción de la identidad homosexual a partir del referente femenino" (74). Agrega que esta tendencia fue registrada por los teóricos de la época: "En 1860 U Irichs definelo que más tarde se llama homosexualidad empleando el término 'uranismo'. U ranistas son varones que 'tienen, de manera congénita e irreductible, un alma de mujer dentro del cuerpo masculino, y sólo pueden conocer el deseo y el placer de la pasión por los hombres viriles'. Pero a finales de 1860, ya se teoriza acerca de cómo esa 'alma de mujer' no es patrimonio exclusivo de los 'uranistas': "M agnus $\mathrm{H}$ irschfeld, fundador de lo que puede considerarse la primera organización homosexual de la historia, sigue en la línea de Ulrichs, (pero) defen- 
dad revolucionaria (hipermasculina) y 3. para mostrar la connotación revolucionaria de la "amoralidad" del homosexual.

El mismo Puig, citado por D above (1994), aclara la elección del personaje:

M e interesaba un personaje femenino que creyese todavía en la existencia del macho superior, y lo primero que se me ocurrió fue que hoy ese personaje no podía ser una mujer, porque una mujer de hoy día ya duda, a estas alturas, que exista ese partener que la va a guiar en todo. En cambio un homosexual, con fijación femenina, sí, todavía puede defender esa ideología, porque como de sea ser mujer pero no puede realizar esa experiencia, no puedellegar a desengañarse, y sigue en el engaño, en el sueño (31).

Adicionalmente, explica M uñoz (1987), "M olina (...) hace visible el lado reprimido del hombre heterosexual" (79).

El hecho de que anatómicamente M olina sea percibido como un hombre, antes y fuera de la isla-mujer, pero como un hombre que ama a los hombres, es decir, un homosexual que, alegóricamente, representa al filántropo (un hombre que ama a "el hombre" en su sentido universal), permite comparar su filantropía con la del revolucionario y, por esta vía, permite oponer dos formas de ser hombre, dos masculinidades y, en sentido más amplio, dos formas de ser persona: la del hombre que ama al hombre-individuo (ama a la humanidad que se encarna en la persona individual), y la del hombre imposibilitado para amar al hombre-individuo, porque, desde la perspectiva revolucionaria, este amor dirigido a una persona concreta, que ata y genera dependencias afectivas, entorpecería la lucha. Se puede hacer una aproximación a las "filantropías" de Valentín y M olina a través de sus formas de narrarse:

diendo la teoría de que todo varón tiene al go de femenino, por lo que todo varón es potencialmente mujer y viceversa" (76). Casi un siglo después, a partir del gay pride (movimiento político cuya génesis fue la denuncia y oposición a los atropellos de la fuerza pública contra quienes asistían a bares para personas con prácticas o identidades homosexuales en Nueva York. El "florero deL lorente" en este caso fue el asalto de la policía al bar Stonewall -sector de Greenwich Village- en junio de 1969) se empieza a construir, tanto teórica como fácticamente, la identidad homosexual a partir del referente masculino-viril. H oy, a pesar delos logros políticos delos movimientos homosexualistas en el mundo, la categoría de homosexual sigue siendo problemática. Bersani (1995) lo explica en estos términos: "O nce we agreed to be seen, we also agreed to be policed" (12). Pero lo que facilita el control y la dominación es la inscripción de la categoría de gay o de homosexual en la estructura bipolar maniquea del sistema patriarcal heterosexista que atrapa los cuerpos en las representaciones que formula de las categorías: "And yet precisely because homosexuals cannot be eliminated (...) the illusion that they exist only out there, must at all costs be manteined" (29). El tránsito hacia lo femenino y no hacia lo homosexual liberaría de este problema. 
Valentín

El gran placer es otro, el de saber que estoy al servicio de lo más noble, que es... bueno... todas mis ideas... (33).

- ¿Y en vos no pensás?
Molina

- M irá, a mí salir me importa más que nada por la salud de mamá. Pero me queda la preocupación de que a vos no te va a... cuidar nadie. - No (245).

Por amor ambos están dispuestos al sacrificio, pero uno sublima ${ }^{8}$ su amor al hombre, dirigiéndolo a un ser más abstracto que el hombre: la humanidad; el otro lo libera. La homosexualidad se emplea, entonces, como símbolo de la verdadera filantropía: amar a "el hombre" (persona, hombre o mujer, concreta) es la verdadera revolución; mientras que la masculinidad revolucionaria, falsa filantropía, simple sublimación del deseo, se relaciona con la autorrepresión.

Pero, más allá de la utilidad axiológica de usar un personaje que sea percibido como hombre y homosexual, ¿M olina es realmente un hombre homosexual como afirma el mismo Puig? Cuando Valentín le pregunta a M olina si todos los homosexuales son como él, éste responde:

$\mathrm{No}$, hay otros que se enamoran entre ellos. Yo y mis amigas somos mujer. Esos jueguitos no nos gustan, esas son cosas de homosexuales. Nosotras somos mujeres normales que nos acostamos con hombres (207).

Con esta respuesta, Puig evidencia quela homosexualidad de su personaje es sólo una de las múltiples expresiones de esta orientación y, de esta manera, evita quese produzca un efecto de representación en loslectores. Pero, adicionalmente, descarta la homosexualidad como tema. Primera aclaración: M olina no es un hombre, así lo subraya el final dela novela: es aceptada como mujer por Valentín y muere como una heroína de película. Decir que es un hombre es negar su capacidad fáctica de subvertir el discurso hegemónico patriarcal heterosexista: M olina es un alienado pero también es un inmoral, en eso consiste su disloque del sistema opresor. Decir que es un hombre también es negar el poder de la isla-mujer para salvaguardar su identidad. Segunda aclaración: si es mujer y le gustan los hombres, no es homosexual. M olina no puede ser un homosexual porqueno es un hombre. Su conflicto es quees una mujer heterosexual, percibida como un hombre homosexual ${ }^{9}$.

\footnotetext{
${ }^{8}$ El concepto de sublimación es referido ensayísticamente en nota de pie de página por el narrador "como una variante del concepto de represión". Agrega que "Freud introdujo el término 'sublimación', entendiendo por ello la operación mental mediante la cual se canalizan los impulsos libidinosos inconvenientes" (168).

${ }^{9}$ M olina no es homosexual sino transgenerista.
} 


\section{EL ESTEREOTIPO DE MUJER Y LA MUJER UTOPICA}

A ella se le ve que algo raro tiene, que no es una mujer como todas (EI beso, 9).

M olina, según M uñoz (1987), "está compuesto en base a [sic] un estereotipo reconocible, familiar. M olina es una convención. Este personaje, dice Puig, no quiere ni puede cambiar" (61). Así se evidencia en un diálogo de M olina con su compañero de celda:

-[... quesiempresepuedeuno enderezar, y que lo que meconviene es una mujer, porque la mujer es lo mejor que hay.

- ¿Te dicen eso?

-Sí, y eso les contesto... jregio!, jde acuerdo!, ya que las mujeres son lo mejor que hay... yo quiero ser mujer (25).

Pero el tipo de mujer que M olina quiere ser es "una señora burguesa", que se casa con un hombre para toda la vida (50), del tipo de las heroínas de sus películas. Una mujer devota a su hombre y signada por la fatalidad. "Yo siempre con la heroína" (31), dice cuando Valentín le pregunta con quépersonaje deCat Woman se identifica, aunque la heroína casi siempre muereal final de la película, como símbolo del sacrificio.

Al tipo de mujer que encaja en ese estereotipo Valentín la percibe como alguien que "fue muy feliz con su marido, que la explotó a su vez a ella, le hizo hacer todo lo que él quiso, que estuviera encerrada en su casa como una esclava, para esperarlo" (22). Pero ese estilo de vida no le desagrada a M olina. Acepta explícitamente el lugar subordinado que anhela para sí como mujer: "Bueno, esto es muy íntimo, pero ya que querés saber... La gracia está en que cuando un hombre te abraza... le tengás un poco de miedo" (246-247).

Valentín opone a esa concepción la nueva mujer: "Para ser mujer no hay que ser... qué sé yo... mártir. M irá... si no fuera porque debe doler mucho te pediría que me lo hicieras vos a mí [penetrarlo], para demostrarte que eso, ser macho, no da derecho a nada" (247). Y resalta la fal sedad del estereotipo de M olina: "te hicieron el cuento del tío los que tellenaron la cabeza con esas macanas" (247). Pero el tipo demujer queprefiereser M olina esfuncional para el efecto axiológico de la novela. Así lo explica M uñoz: "M olina, a pesar de su resistencia al cambio, hace visible el lado reprimido del hombre heterosexual. Por su identificación con la mujer, muestra la explotación sufrida por ésta en la sociedad patriarcal" (1987: 79).

Frente a los argumentos a favor de la equidad entre géneros que esgrime Valentín, M olina presenta su necesidad vital de realización en ese tipo demujer: 
- ¿Pero no te das cuenta que todo eso es un engaño? Si fueras mujer no querrías eso.

- Yo estoy enamorado de un hombremaravilloso, y lo único que quisiera es vivir al lado de él toda la vida.

- Y como eso es imposible, porque si él es hombre querrá a una mujer, bueno, nunca te vas a poder desengañar (50).

Aunque Valentín le ha negado brutalmente su deseo, al final de la novela se convierte en el hombre que le permite devenir mujer, incluso el tipo de mujer que M olina ha deseado (la del estereotipo: sacrificada, abnegada y complaciente). Pero insiste: "Y prometeme otra cosa... que vas a hacer que te respeten, que no vas a permitir que nadie te trate mal, ni te explote. Porque nadie tiene derecho a explotar a nadie (...) M olina, prometeme que no te vas a dejar basurear por nadie" (265). M olina lo promete. Sin embargo, por amor a su hombre (Valentín) acepta la misión que le cuesta la vida. Su muerte es la realización de su devenir mujer-heroína de película.

\title{
EL H OMBRE-HEROE-SEM IDIOSY EL H O MBRE H UM AN IZADO
}

\author{
Al haber oído queél es capaz de condenar a muer- \\ te $a$ alguien, se le ha venido abajo como hombre \\ (M olina, El beso: 88).
}

Valentín es un hombre revolucionario de izquierda: "Está lo importante que es la revolución social, y lo secundario que son los placeres de los sentidos" (33). La causa subordina su cuerpo y a todos los cuerpos. Los afectos, que son personales, que se dirigen de un cuerpo a otro, son inválidos si lo arrebatan de la lucha. Cuando Valentín confiesa su deseo de abrazar a su compañera de lucha y su temor porque le pase al go, M olina le aconseja:

- Escribile, decile que no se arriesgue, que vos la necesitás.

- Eso nunca. Si vas a pensar así nunca vas a poder cambiar nada en el mundo (48).

Valentín va siendo atrapado por las narraciones de películas de M olina hasta el punto de depender de ellas. Pero al principio tiene claras sus prioridades. Cuando M olina le ofrece continuar el relato la mañana siguiente, Valentín le responde: "N o, mejor a la noche, durante el día no quiero pensar en esas macanas. H ay cosas más importantes en qué pensar" (15).

A ese tipo de hombre, tan instalado en el estereotipo de hombría, como el psicoanalista deC at Woman con el cual se identifica: "con un bigotico medio de 
hijo de puta, no sé si me explico, un bigote de cancherito, que lo vende" (26), M olina opone como objeto de deseo al protagonista de esa película "porque es un tipo pacífico y comprensivo" (23). El tipo de masculinidad que lo hizo enamorarse de Gabriel, una masculinidad decidida, pero no violenta ni sobradora: "este hombre sin perder la calma le contestó lo que debía (...) Pero no te creas que estuvo sobrador tampoco, nada, distante, perfectamente dueño de la situación. Y yo enseguida me olí que ahí había algo, un hombre de veras" (68).

En todo caso, el tipo de hombre que encarna Valentín (al principio), si bien es criticado por M olina, también lo seduce. En cambio, desdela perspectiva del narrador ensayista, es abiertamente condenado:

Altman y la escuela marcusiana condenan el estereotipo del hombre fuerteque se les presenta a los varones como model o más deseable a emular, ya que dicho estereotipo propone tácitamente la afirmación de lo masculino mediante la violencia, lo cual explica la vigencia constante del síndrome agresivo en el mundo (n.p.p.: 200).

Las expresiones de violencia de Valentín contra M olina se ubican en el plano simbólico, no comprendesu falta de compromiso, su adscripción burguesa, que subordine el gusto estético en una película a la forma y no al contenido, y lo critica bruscamente. Ante esa brutalidad masculina, M olina se yergue en una actitud femenina casi anacrónica y, sin embargo, más evolucionada, en cuanto al trato humano, que la de Valentín. D emerita la revolución al reducirla al ámbito del hombre guerrero brutal. Es mejor ser mujer que revolucionario o torturador:

- ¿Y quétiene de malo ser blando como una mujer?, ¿por quéun hombreo lo que sea, un perro, o un puto, no puede ser sensible si se le antoja? - No sé, pero al hombre ese exceso le puede estorbar. - ¿Para qué?, ¿para torturar? - No, para acabar con los torturadores.

-Pero si todoslos hombresfueran como mujeres no habría torturadores(35).

En el mismo sentido, Leni, la heroína de la película nazi, evidencia que el valor de su héroe puede ser una faceta del miedo: "Ella le pregunta entonces si no es por miedo que se mata a un enemigo indefenso, por miedo de que en al gún momento se inviertan los papeles y haya que hacerle frente, mano a mano tal vez" (87).

Interpretando la película sobre Leni, M olina deja ver también que no hay diferencia en la expresión autoritaria de la masculinidad entrelas extremas derecha e izquierda. Un héroe de izquierda es como un héroe nazi: 
(...) esas especies de oleadas de violines son las aguas de un río alemán por donde navega un hombre-dios, que no es más que un hombre pero que su amor a la patria le quita todo miedo, ése es su secreto, el afán de luchar por su patria lo vuelve invencible (...) a él se le llenan los ojos de lágrimas (...) ella al verlo conmovido, se da cuenta que él tiene los sentimientos de un hombre, aunque parezca invencible como un dios. El trata de esconder su emoción y va hacia el ventanal (62).

Esconder la sensibilidad humana (debilidad para el héroe, belleza humana para la heroína) es negar el cuerpo y el deseo. Esto ha sido lo que ha condenado, según la interpretación del propio Valentín, a I rena, la mujer pantera (Cat people, 1942). A través de su historia se denuncian los efectos de la represión de la sexualidad: "parecen mujeres normales, pero si un hombre las besa se pueden transformar en una bestia salvaje" (19). La práctica sexual liberaría el instinto animal de aquella mujer que se ha reprimido, interpreta Valentín. El animal reprimido (libido) se libera y asesina al ser humano, pero es parte de él, así que mueren ambos. ¿Q ué pasa con la represión de las emociones que se impone el hombre que considera que éstas estorban a su causa revolucionaria? La causa de M olina consiste en hacer las cosas por las personas que ama: Gabriel, su mamá, Valentín; eso lo libera. En cambio, la causa revolucionaria de Valentín lo ha llevado a reprimir sus sentimientos. Pero, con el paso del tiempo, Valentín deja de esconder su propia emoción, deja de reprimirse gradualmente:

- Al final, Valentín, vos también tenés tu corazoncito.

- Por algún lado tiene que salir... Ia debilidad, quiero decir.

- No es debilidad, che.

- Es curioso que uno no puede estar sin encariñarse con algo... Es... como si la mente segregara sentimiento, sin parar... (47).

Valentín, además, se debate entre su compañera de lucha y el tipo de amor aburguesado que aún siente por $\mathrm{M}$ arta, su antigua compañera: "porque me parece que $M$ arta sola me podría revivir, porque me siento muerto, te juro. Tengo la impresión de que nada más que ella me podría revivir" (180). M olina, "la mujer burguesa" quelo cuida, y M arta (su evocación) quien comparte con él su origen burgués dejan que libere su "debilidad" reprimida por su deber-ser de hombre revolucionario: "me da rabia ser mártir, no soy un buen mártir, y en este momento pienso si no me equivoqué en todo [...] tengo miedo porque estoy enfermo... y tengo miedo... miedo terrible de morirme" (182).

I gualmente, hacia el final de la novela, los relatos improductivos de M olina (tiempo de ocio) han desplazado las lecturas productivas de Valentín e incluso han ocupado el tiempo que debe ser para la productividad: el día. 
Pero la transformación de Valentín no es en relación con el estereotipo de feminidad ni a partir de un estereotipo de masculinidad. El es consciente de la dominación que se ejerce a través del mecanismo de la sexualidad y de la necesidad de liberarse como parte de un proceso revolucionario. M ientras que para M olina ser hombre, como objeto de deseo, parte del cuerpo anatómicamente masculino: "ser lindo, fuerte, pero sin hacer alharaca de fuerza, y que va avanzando seguro (...) que hable sin miedo, que sepa lo que quiere, adonde va, sin miedo de nada" (69). Para Valentín, el ideal de hombre está cerca de su ideal de persona, no es un asunto de género ni de anatomía sino de humanidad: "no dejarme basurear [...] no rebajar a nadie con una orden, con una propina [...] no permitir que nadie al lado tuyo se sienta menos, que nadie al lado tuyo se sienta mal" (70). Y su tránsito es hacia devenir persona. El tipo de persona que a pesar de la asignación cultural del género masculino a partir de la anatomía de su cuerpo, es capaz deliberarsea través de su feminidad, desu sexualidad polimorfa.

\section{LA ISLA-CELD A}

Y lo lindo de cuando uno se siente feliz, sabés Valentín... es que parecequees para siempre, quenunca más uno se va a sentir mal (M olina, El beso: 238)

Para M anrique (2000), en el curso de la novela ocurre una transformación simétrica entre los dos protagonistas:

M olina, la loca frívola, empieza a interesarse en la miseria del mundo a través de sus conversaciones con Valentín. Valentín (el marxista frío y sin imaginación) aprende de M olina que no podemos separar la mente del corazón y que la fantasía puede ser una fuerza liberadora [...] Inicialmente, Valentín es el D on Q uijote que quiere transformar el mundo y M olina es su Sancho Panza. Al final, M olina acepta su responsabilidad política y decide salir al mundo a ayudar en la lucha contra los molinos de viento. Cuando M olina muere y Valentín es torturado, lo único que lo mantiene vivo es su capacidad para la fantasía (que ha aprendido de M olina) (91).

Es excesiva la simetría que M anrique propone. No es evidente (ni verosímil) que Molina haya adquirido una conciencia política que lo haya llevado a la causa revolucionaria de la noche a la madrugada. En la noche ha advertido a Valentín queno asumirá la misión; unas horas después, mientras hacen el amor, está dispuesto a aceptar y lo dice después de ser besado por primera vez por su hombre. Lo hace por amor. Porque su forma de ser mujer hace que asuma así el amor, como una heroína de sus películas. Como Leni, quien muerecumpliendo 
su misión, después de haber dudado acerca de cuál era el bando correcto; igual que M olina, exactamente igual.

La transformación que ocurre a los personajes es solamente la transformación posible, la que cabe en sus estructuras mentales. De hecho, M olina no cambia su estructura mental. Su devenir consiste en realizar su utopía: ser amada por un hombre como mujer. Es más claro un sentido de aprendizaje hacia la transformación en Valentín, quien se va liberando del deber-ser que le impone ser un héroe revolucionario. Pero el curso de ambos tránsitos hacia la realización, en el primer caso, y en el aprendizaje, en el segundo, tiene su punto más alto en el beso. Punto de unión entre las revoluciones política y sexual. Punto a partir del cual los dos personajes se involucran en la causa que les era menos propia.

M olina rechaza el lugar en la relación de poder masculino-femenino que la cultura le asigna por su sexo anatómico; Valentín rechaza tal relación de poder en sí misma. La realización de M olina pende de la existencia de los roles para asumir el femenino, la deValentín consiste en erradicarlos desí mismo o dejarse habitar por ambos.

Pero la elección de la fatalidad asociada a la mujer estereotípica, única forma de ser mujer que concibe para sí mismo Molina, por ser elección, no conlleva predestinación, como afirma Dabove: "D evenir-mujer es abandonarse, ya haberse abandonado a algo que va a ocurrir o que en rigor ya ha ocurrido, en un pasado del que no se tiene constancia ni memoria: su consumación sería la forma visible del D estino" (1994: 30). Elegir esa fatalidad es la vía para su real ización como el tipo de mujer que concibe. En todo caso, ese devenir mujer, a pesar de su esfuerzo por ajustarse a sus modelos estereotípicos, deja traslucir una feminidad más auténtica y esencialmente femenina que Valentín logra percibir en ella y que asocia al simbolismo esencial. M olina es mujer, tierra, agua, satisfacción de las necesidades del cuerpo y fuente de respuestas.

Pero ambas, tanto la realización como mujer estereotípica de M olina, como la transformación en el tipo de persona más liberada del esquema opresor-oprimido, incluido un grado de liberación del disciplinamiento heroico-racional de Valentín, son etapas en el proceso de subversión de la dominación moral (patriarcal-heterosexista sobre los cuerpos). La primera está realizada y es el final feliz para M olina: la muerte como sacrificio por amor. Para Valentín, acceder a su feminidad es sólo parte del proceso, por eso debe mantenerse en la lucha.

La transformación-depuración que ocurre a los personajes está marcada por la exacerbación de las tensiones de la novela en el capítulo diez. La presión del deber-ser de las fuerzas que operan en lo público se opone a una conciencia de relación íntima y libre que empieza a levantarse al rededor de los protagonistas como barrera que los protege del exterior. La tensión se expresa en crisis de conciencia para los dos personajes (traición-cuidado, manipulación-gratitud). 
Cada uno guarda en silencio un relato que el otro ignora; ambos son revelados al lector en paralelo con la película La vuelta dela mujer zombi. Allí se postula la resolución ética de los conflictos de conciencia.

La libertad de M olina depende de que traicione (una "sonámbula traidora") a Valentín; sin embargo, verlo enfermo, debilitado y devuelto a su dimensión humana (liberado de su deber-ser heroico-revolucionario) desata su actitud femenina a través del estereotipo de mujer que cuida: la enfermera: "La pobre enfermera, no tiene suerte, le dan el enfermo más gravey no sabe que hacer para que esa noche no muera o no la mate, más fuerte que nunca el peligro al contagio" (177). El riesgo de muerte también es percibido por Valentín en su relato privado que deja ver la faceta más agresiva de su masculinidad: El revolucionario se aprovecharía de la psicología de M olina para manipularlo. Conoce su "corteza cerebral de perro, asno, caballo, de mono, de hombre primitivo, de chica de barrio que entra al cine por no ir a la iglesia" (192).

Esto pone a la heroína entre los fuegos cruzados de los dos extremismos, el de izquierda y el de derecha, como le ocurre a Leni con los nazis y los maquís. En el metarrelato privado de M olina, paralelo al de Valentín, la enfermera teme la muerte del enfermo o la suya a manos de él o el contagio (dejarse persuadir). Entre tanto, Valentín es el portador de "la fría mirada del verdugo culto sobre una pobre corteza inocente de chica de barrio, de puto de barrio" (192). Y es consciente de que está poniendo en riesgo la vida de M olina:

(... ) pobre la cabeza que rueda del puto de barrio, ya no hay más remedio, ya no se la puede pegar a su cuerpo, cuando ya está muerta hay que cerrarle los ojos abiertos a esa cabeza, y acariciarle la frente estrecha ¿besarle la frente? La frente estrecha que tapa los sesos de chica de barrio iquién dio la orden de guillotinarla?El verdugo culto obedecela orden queno sabededóndellega (193).

El cumplimiento de esta orden (coherente con la jerarquización revolucionaria, tan similar a la reaccionaria) en todo caso es conflictiva. Esto explica su reacción violenta ante los mimos de M olina la mañana siguiente.

Pero las tensiones de los dos personajes entre lo que deben hacer (racional) y lo que quieren hacer (emocional) se resuelve en el otro metarrelato, paralelo a éstos. El deber hacer está simbolizado en la mujer zombi que ama pero debe matar a su amado porque ella no es dueña de su voluntad y debe cumplir las órdenes del brujo. Alienada, tanto como el pueblo de esclavos zombis, al servicio del capitalismo de los hacendados ${ }^{10}$ : " $\mathrm{Y}$ en los ojos de la zombi se ve que no

\footnotetext{
${ }^{10}$ La causa de la revolución es la liberación de los alienados: "unos pobres peones se habían rebelado contra los dueños porque les pagaban poco, y los dueños se pusieron de acuerdo con el brujo principal de la isla para que los matara y los convirtiera en zombis, y así fue que después de
} 
creelo quele diceel brujo, pero nada puedehacer ella, porque no es dueña de su voluntad, y no puede hacer más que obedecer las órdenes del brujo" (214). La mujer zombi muere, la sonámbula traidora desiste. Entre dejar morir, dejarse matar y el contagio, impera esteúltimo: "El paciente más grave del pabellón ya está fuera de peligro, la enfermera velará toda la noche sobre su sueño tranquilo" (216).

\section{LA ISLA-MUJER}

Este sueño es corto pero es feliz (Valentín, El beso: 287).

Pero, si en el relato metadiegético que se hace M olina a sí mismo, la enfermera está en riesgo de ser contagiada por el enfermo, en la relación diegética es la enfermera la que contagia al enfermo. El mecanismo de la transformación (el contagio), obra a través del afecto que se genera en este punto entre los dos reclusosy en su decisión de no traicionar (M olina) y no manipular (Valentín) ${ }^{11}$. El cuidado de la enfermera y el aprendizaje que al canza a su lado lo fortalecen. Separa el mundo público, gobernado por las luchas por el poder sobre los cuerpos, del mundo íntimo. El enemigo está afuera y desde allí no debe poder destruir las posibilidades de relación, relativamente libres de la dominación, que empiezan a construir los dos reclusos. Así lo explica Valentín: "estamos los dos acá encerrados, y no hay ninguna lucha, ninguna batalla que ganarle a nadie" (205). Y se cuestiona: “ ¿es posible que pueda tanto... el enemigo que está afuera? (...) todo lo que está mal en el mundo, y que yo quiero cambiar, ¿será posible que no me deje actuar... humanamente ni un solo momento?" (206).

M ás adelante, introduce la noción de isla como territorio que resguarda la intimidad:

En cierto modo estamos perfectamente libres deactuar como queremos el uno respecto al otro, ¿me explico? Es como si estuviéramos en una isla desierta.

muertos los hicieron trabajar en las cosechas de bananas [...] no hablan, no tienen ya voluntad y lo único que pueden hacer es obedecer y sufrir" (173); pero el conflicto de los dos personajes en este punto es justamente que sus voluntades no les pertenecen, como unos alienados ellos mismos: están obligados (M olina por el director, Valentín por sus compañeros de causa) a actuar en contra del afecto que se ha despertado entre ellos y traicionar (M olina) o manipular (Valentín).

${ }^{11}$ Si bien la posibilidad de que Valentín sí haya aceptado la orden de manipular no se puede excluir (su resolución se hace más ambigua por cuanto persuade a M olina de aceptar una misión en la que pierde la vida), hay más evidencias para el egir la transformación (devenir persona) del revolucionario como interpretación del desarrollo de este personaje. 
Una isla en la que tal vez estemos solos años. Porque, sí, fuera de la celda están nuestros opresores, pero adentro no. Aquí nadie oprimea nadie. Lo único que hay, de perturbador, para mi mente... cansada, o condicionada o deformada... es que al guien me quiere tratar tan bien, sin pedir nada a cambio (206).

Si antes la realización de los placeres del cuerpo era imposible y estaba vedado siquiera mencionarlos:

- No hables de comidas.

-Y panqueques...

- D everas, te lo pido en serio. $\mathrm{N}$ i de comidas ni de mujeres desnudas (20).

Ahora pueden comer y disfrutar del erotismo. La transformación ha obrado. El erotismo significa la posibilidad de comunicarseíntimamente, esto es, sin la mediación de los prejuicios o normas que dominan lo público. Su punto culminante es e beso. Es la posibilidad de devenir otro y ser en el otro. Así lo percibe M olina:

- Ahora sin querer mellevé la mano a mi ceja, buscándome el lunar. - ¿Q ué lunar?...Yo tengo un lunar, no vos (222).

Enseguida, agrega: "M e pareció que yo no estaba... que estabas vos solo (...) 0 que yo no era yo. Q ue ahora yo... eras vos" (222). Valentín también lo percibirá así más adelante. Comparte con M olina el sentimiento satisfactorio de ser en el otro, de ser a través del otro:

-(...) Y es que cuando me quedo solo en la cama ya tampoco soy vos, soy otra persona, que no es ni hombre ni mujer pero que se siente...

-... fuera de peligro.

-Sí, ahí está, ¿cómo lo sabes?

- Porque es lo que siento yo (238).

D above opina queel planteamiento utópico dela novela a través deValentín consiste en que:

D ado que habitar una de las opciones (hombre-mujer) equivale a una forma de alienación, pluralizar los comportamientos, pasar de uno a otro indistintamente, es o puede ser sinónimo de libertad. La bisexualidad sería la solución y la moralidad hacia la que inevitablemente se nos conduciría (35).

Cuando M olina tome la forma de la nativa o de la mujer araña o de la isla misma, en el sueño anestésico tras la tortura, Valentín expresará que ha sido habitado por y ahora habita en la feminidad, por y en M olina: "esta isla es una 
mujer" (284). M olina estará en Valentín y satiffará su hambre, proveerá sus necesi dades. Esta satiffacción del hambre simboliza una nueva forma de acceder al conocimiento para Valentín:

-Aprendí mucho con vos, Molinita...

-Estás loco, si yo soy un burro...

- Y quiero que tevayas contento, y tengas buen recuerdo de mí, como yo lo tengo de vos.

- ¿Y qué es lo que aprendiste de mí?

-Es muy difícil de explicar. Pero me has hecho pensar mucho, esto te lo aseguro (265).

Saber ya no es resultado exclusivamente del consumo racional teórico; como anota M uñoz, es también "comer, entender con el cuerpo": "La mujer-araña me señaló con el dedo un camino en la selva, y ahora no sé por dónde empezar a comer tantas cosas que me encontré" (1987: 286). Valentín evidentemente ha cambiado, acepta la no racionalidad de M olina - "chica de barrio que entra al cine por no ir a la iglesia" (192)- como una fuente válida de saber. Pero la utopía sólo llega hasta ahí: se expande por los dominios de la isla, pero no por los de la celda, símbolo dela opresión que trasciendelosmuros: muerte, tortura, el mundo que sigue esperando la revolución. Y el desenlace resalta simultáneamente los sentimientos deopresión y liberación-realización. N o hay espacio para la utopía política: el sistema sigue controlando los cuerpos, sin embargo, se anuncia que las sexualidades han sido liberadas y satisfechas: M olina ha sido amada por un hombre y, después de desear que la felicidad dure: - "Y lo lindo de cuando uno se siente feliz, sabés Valentín... es que parece que es para siempre, que nunca más uno se va a sentir mal" (238)- , eligela muerte (como presentimiento, como asunción de su ideal de mujer heroína de película o como simple comprensión de que la felicidad no dura): "C ada vez que has venido a mi cama... después... quisiera, no despertarmemás una vez que me duermo (...) de veras lo único que pido es morirme" (239).

Y muere, pero muere sabiendo que fue amada. En las películas y en la vida, la felicidad no puede durar: en las primeras, uno de los protagonistas deberá morir ${ }^{12}$, y en la segunda, según dice Valentín: "En la vida del hombre, que puede ser corta y puede ser larga, todo es provisorio. N ada es para siempre (...) habría que saber aceptar las cosas como se dan, y apreciar lo bueno que te pase,

\footnotetext{
${ }^{12}$ Concuerdo parcialmente con M uñoz en que, a través de este tipo de desenlaces, "cada película, a su modo, sugiere que el individuo no puede propulsar ningún tipo decambio en un mundo regido por fuerzas ajenas, desconocidas, inmutables" (1987: 66): no puede cambiar el mundo, pero puede cambiarse a sí mismo o realizarse.
} 
aunque no dure" (263). D ándole ese sentido le había explicado a M olina el desenlace de Flores negras: "Q uiere decir que aunque ella se haya quedado sin nada, está contenta de haber tenido por lo menos una relación verdadera en la vida, aunque se haya terminado" (263).

El altruismo de cada uno implica sacrificio de sí. M olina da la vida por una persona, Valentín quiere ser un mártir y lo es, pero la imaginación, contagiada por la enfermera al enfermo, ha sido su fuerza. La posibilidad de que muera la heroína y no el héroe (la más común en las películas relatadas por M olina) debe dar un sentido a la supervivencia del héroe. El final es triste, pero no del todo, el héroe ha ganado algo, ha sido contagiado de algo: "Y él camina solo pero por un camino lleno de sol. Fin" (100).

La convivencia, la tolerancia y el amor han sido la vía del contagio. Según M uñoz, "el beso traicionero de la mujer pantera, que destruye, se convierteen el beso de la mujer araña; una araña cuya tela, lejos de atrapar a Valentín, le ofrece la oportunidad de humanizarse" (1987: 78). Así lo reconoce también Valentín: "Es cierto, no sos la mujer pantera [...] Vos sos la mujer araña, que atrapa a los hombres en su tela" (265).

Para Valentín, superados sus prejuicios, M olina es más que un puto de barrio 0 una señora burguesa: su esencia es la feminidad. M olina es la tierra, el agua, el alimento, la isla, el refugio, la protección, la fantasía, el sueño; M olina es la mujer, todas las mujeres, todas menos la mujer pantera, porque la sexualidad de M olina no está enferma, no está reprimida en espera de la ruptura del dique; es salud, no violencia potencial. Es todas las mujeres, pero principalmente la mujer araña:

la tel araña le crece del cuerpo de ella misma, de la cintura y las caderas le sal en los hilos, es parte del cuerpo de ella, unos hilos peludos como sogas que me dan mucho asco ${ }^{13}$, aunquetal vez acariciándolos sean tan suaves como quién sabe qué(285).

Y ése tal vez hace de Valentín el nuevo hombre, polimorfo sexual, llamado a habitar esa isla que es mujer, llamado a ser habitado por esa mujer: "Vivo dentro de tus pensamientos y así te voy a acompañar siempre" (286). Fin.

${ }^{13}$ El relato alegórico a esta tensión entre el asco y el presentimiento de un placer más allá del prejuicio de la apariencia ha sido M ilagro de amor: la superficie, el cuerpo, no importa: "ustedes son hermosos el uno para el otro, porque se quieren y ya no se ven sino el alma" (115) o se ven el cuerpo pero liberados del prejuicio moral. 


\section{REFERENCIAS}

Bersani, Leo. 1995. H omos. Cambridge: $\mathrm{H}$ arvard U niversity Press.

Dabove, Juan Pablo. 1994. La forma del destino. Sobre El beso de la mujer araña de $M$ anuel Puig. Buenos Aires: Viterbo.

Guasch, 0 scar. 1995. La sociedad rosa. Barcelona: Anagrama (primera edición de1991).

M anrique, Jaime. 2000. M aricones eminentes. Arenas, Lorca, Puig y yo. Bogotá: Alfaguara (original en inglés, 1999).

M ercanton, Jacques. Sin año. "James Joyce". En: Joyce, James. Ulises. Buenos Aires: C.S. Ediciones.

M uñoz, Elías M iguel. 1987. El discurso utópico de la sexualidad en M anuel Puig. M adrid: Pliegos.

Puig, M anuel. 2002. El beso dela mujer araña. Barcelona: Seix Barral (primera edición de 1976). 